\title{
Stability of Ferrous Fumarate in Medicaments for Women: Application of Mössbauer Spectroscopy
}

\author{
M. KĄDZIOŁKA-GAWEE* AND M. WOJTYNiAK \\ Institute of Physics, Silesian University, Uniwersytecka 4, 40-700 Katowice, Poland
}

(Received October 5, 2015; in final form March 22, 2016)

\begin{abstract}
Determination of the iron state $\left(\mathrm{Fe}^{2+}\right.$ or $\left.\mathrm{Fe}^{3+}\right)$ and content of iron in commercial pharmaceutical products containing ferrous fumarate $\mathrm{FeC}_{4} \mathrm{H}_{2} \mathrm{O}_{4}$ was made by the Mössbauer spectroscopy and X-ray fluorescence method. Also, influence of thermal treatment on stability of ferrous fumarate in selected medicaments has been investigated. The investigated samples were annealed in definite temperature: 373,473 , and $573 \mathrm{~K}$ for $5 \mathrm{~h}$. Room temperature Mössbauer spectra of initial samples gave clear evidence that two phases of iron were presented. The major component was connected with ferrous fumarate with a contribution from $\approx 85 \%$ to $\approx 50 \%$, depending on investigated medicaments. Ferrous fumarate was stable up to annealing temperature $473 \mathrm{~K}$. Above this temperature significant oxidation of $\mathrm{Fe}^{2+}$ to $\mathrm{Fe}^{3+}$ was observed.
\end{abstract}

DOI: 10.12693/APhysPolA.129.1242

PACS/topics: 87.64.kx

\section{Introduction}

Iron plays a very important role in the living systems. It is an integral part of many proteins, enzymes and minerals that work with other substances to create hemoglobin. During pregnancy and after birth, a woman's requirement for iron increases. This requirement increases significantly during pregnancy as maternal blood volume increases and a baby's blood system is developing. Absorption of iron from food requires recognition of the chemical form of iron by gut receptors. Both shape and charge are important in the recognition process. To be absorbed, dietary iron must be in its ferrous form, which is soluble, unless the $\mathrm{Fe}^{3+}$ ion is chelated [1]. Therefore, the knowledge of the iron valence state in medicaments is very important because it may be related to the effect and toxicity of such pharmaceutical product.

Many medicaments used in daily life have a reduced therapeutic effect because of their poor physico-chemical characteristics. Poor solubility, especially of the drugs used in the long-term treatment, can lead to increased number of side effects or does not give any expected effects. Preparations based on iron $\mathrm{Fe}^{2+}$ fumarate are now widely used because of its good properties such as good adsorption affinity in the body, low toxicity and minimal side effects, pure iron $\mathrm{Fe}^{2+}$ fumarate is a compound stable up to temperature $570 \mathrm{~K}[2]$. The Mössbauer spectroscopy is the most sensitive technique for the analysis of iron state [3, 4]. Hyperfine parameters of ${ }^{57} \mathrm{Fe}$ from the Mössbauer spectra like isomer shift $\left(I_{s}\right)$ and quadrupole splitting $\left(Q_{s}\right)$ give information about the iron electron structure, valence and spin state of iron. The content of iron in iron $\mathrm{Fe}^{2+}$ fumarate can be examined with this method.

\footnotetext{
* corresponding author; e-mail: mariola.kadziolka-gawel@us.edu.pl
}

In this work content of iron in selected medicaments has been determined. We also checked how production process affects the content of iron $\mathrm{Fe}^{2+}$ in ferrous fumarate in investigated dietary supplements. Used every day medicaments are stored in various physical conditions. Therefore, the influence of thermal treatment on stability of ferrous fumarate contained in dietary supplements for women using the Mössbauer effect technique was studied.

\section{Experimental procedure}

The following samples of commercially available dietary supplements for pregnant women were chosen for this study: Prenatal ${ }^{\circledR}$ Classic (Furitan's Pride Inc., USA), Pregnacare ${ }^{\circledR}$ Original (Vitabiotics Ltd. United Kingdom) and Falvit ${ }^{\circledR}$ (Jelfa, Poland). All the investigated dietary supplements contained iron in the form of ferrous fumarate $\mathrm{FeC}_{4} \mathrm{H}_{2} \mathrm{O}_{4}$. The studied dietary supplements contained different amount iron per one tablet: $60 \mathrm{mg}$ in Prenatal ${ }^{\circledR}$ Classic, $17 \mathrm{mg}$ in Pregnacare ${ }^{\circledR}$ Original and $14 \mathrm{mg}$ in Falvit ${ }^{\circledR}$.

The chemical composition was determined using X-ray fluorescence (XRF) ZSX Primus II Rigaku spectrometer. The spectrometer, equipped with the $4 \mathrm{~kW}, 60 \mathrm{kV}$ Rhanode and wavelength dispersion detection system, allowed for the analysis of the elements from Be to U. No external standard were necessary, only the internal standards coupled with the fundamental parameters method (theoretical relationship between measured X-ray intensities and the concentrations of elements in the sample) were implemented.

The ${ }^{57} \mathrm{Fe}$ Mössbauer spectra were recorded at room temperature using a constant acceleration spectrometer with ${ }^{57} \mathrm{Co}$ :Cr source, a multichannel analyzer with 1024 channels and linear arrangement of the ${ }^{57} \mathrm{Co}$ source, an absorber and a detector. The values of $I_{s}$ and $Q_{s}$ for all identified subspectra were determined with reference to the centroid of the spectrum of a standard $\alpha$-Fe foil. These Mössbauer spectra were calculated by means of 
a discrete analysis (few doublets and a Zeeman sextet). The Mössbauer investigations were made on powdered samples and were performed at room temperature. Before the measurements all the samples were annealed in air atmosphere in static conditions by $5 \mathrm{~h}$ in definite temperature: 373,473 , and $573 \mathrm{~K}$.

\section{Result and discussion}

Results of XRF analysis showed that examined medicaments contain quantity of iron without much difference with that given by the manufacture. Prenatal ${ }^{\circledR}$ Classic contains $62 \mathrm{mg}$, Pregnacare ${ }^{\circledR}$ Original $15 \mathrm{mg}$ and Falvit ${ }^{\circledR}$ $14 \mathrm{mg}$.

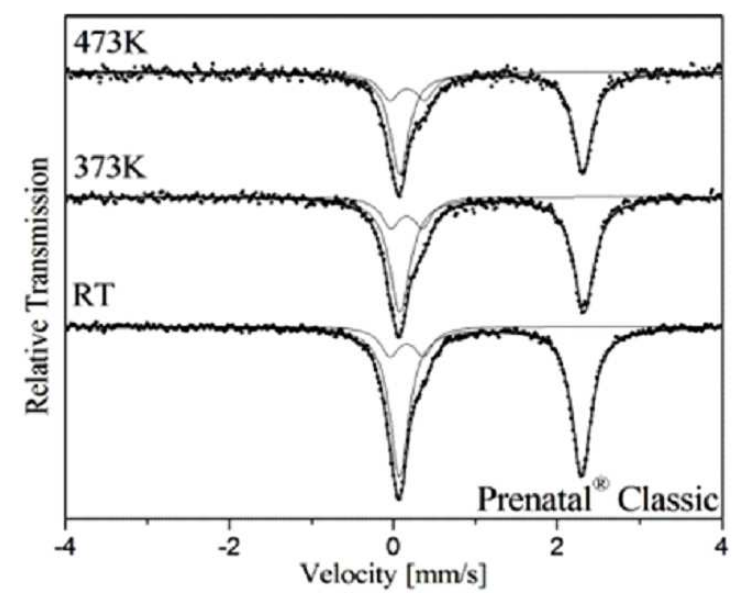

Fig. 1. Mössbauer spectra of Prenatal ${ }^{\circledR}$ Classic for the initial sample and after annealing at $373 \mathrm{~K}$ and $473 \mathrm{~K}$. Fitted subspectra are presented in the spectra.

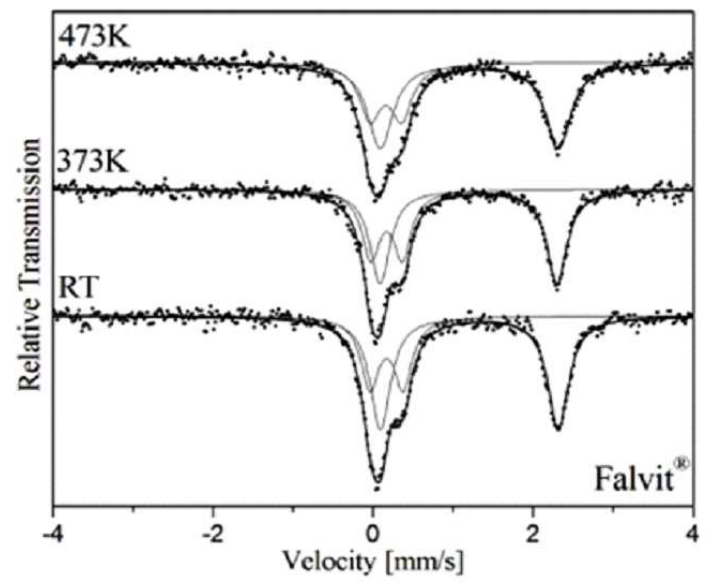

Fig. 2. As Fig. 1 for Falvit ${ }^{\circledR}$.

The Mössbauer spectra of investigated medicaments before and after annealing process are presented in Figs. 1-4. Hyperfine parameters connected with particular subspectra are listed in Table I with experimental errors smaller than 5\%. Previous Mössbauer data for ferrous fumarate were: Is in range from $1.16 \mathrm{~mm} / \mathrm{s}$ to $1.24 \mathrm{~mm} / \mathrm{s}$ and $\mathrm{Qs}$ in range from $2.18 \mathrm{~mm} / \mathrm{s}$ to
$2.24 \mathrm{~mm} / \mathrm{s}$ [3, 5-7]. Hyperfine parameters of main component of all the investigated supplements correspond to ferrous fumarate. The content of $\mathrm{FeC}_{4} \mathrm{H}_{2} \mathrm{O}_{4}$ in Prenatal ${ }^{\circledR}$ Classic is about $85 \%$, in Falvit ${ }^{\circledR} 65 \%$ and only $50 \%$ in Pregnacare ${ }^{\circledR}$ Original. Apart from main component additional components related to the high spin ferric compound were observed in the Mössbauer spectra. Ferric ions accompanying ferrous iron compound contained in dietary supplements were also observed by other authors [3, 5-8]. All observed ferric components have similar hyperfine parameters, but their content is different in investigated medicaments. Existence of these ferric ions can be a result of oxidations of $\mathrm{Fe}^{2+}$ ions in ferrous fumarate to $\mathrm{Fe}^{3+}$ ions in production process used by different producers.

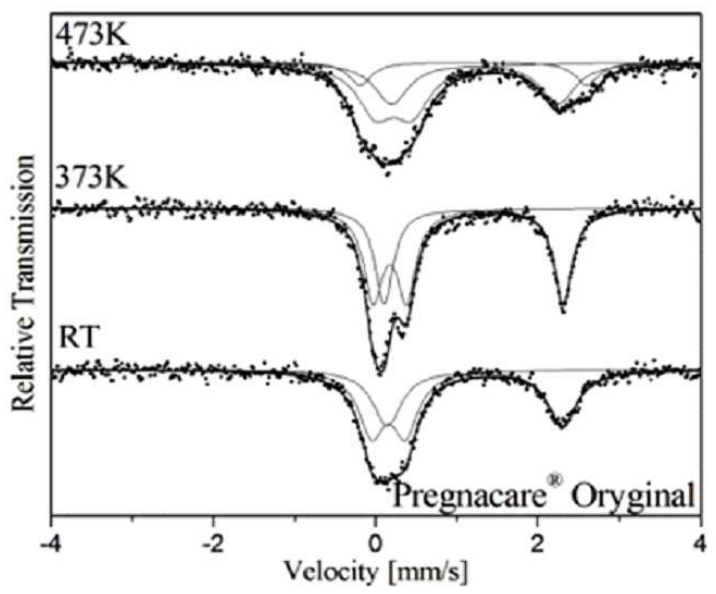

Fig. 3. As Fig. 1 for Pregnacare ${ }^{\circledR}$ Original.

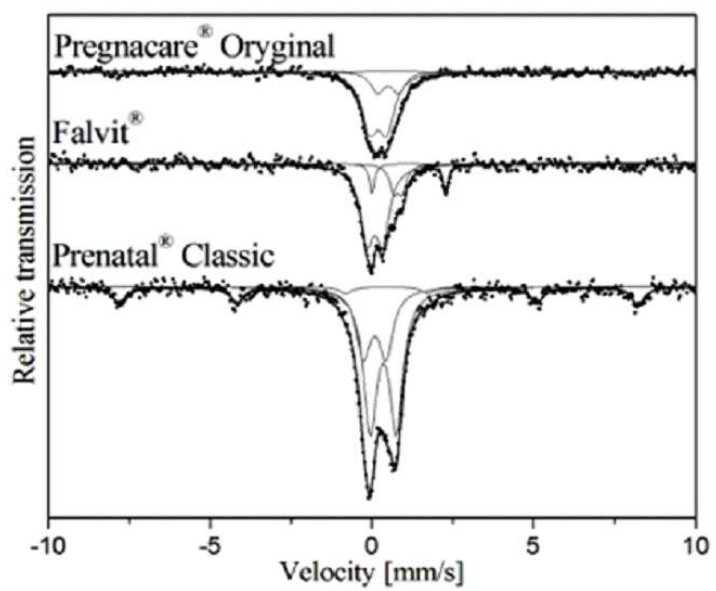

Fig. 4. Mössbauer spectra of investigated dietary suplements: Prenatal ${ }^{\circledR}$ Classic, Falvit ${ }^{\circledR}$, Pregnacare ${ }^{\circledR}$ Oryginal obtained after annealing at $573 \mathrm{~K}$. Fitted subspectra are presented in the spectra.

Annealing process of all the medicaments at the temperature $373 \mathrm{~K}$ leads to homogenization of investigated compound, which is reflected in narrowing of width of absorption lines. It can suggest that iron fumarate was 
TABLE I

Mössbauer parameters of the investigated dietary supplements measured at room temperature before and after annealing process. $I_{s}$ - isomer shift $[\mathrm{mm} / \mathrm{s}], Q_{s}$ - quadruple splitting $[\mathrm{mm} / \mathrm{s}], H-$ hyperfine magnetic field [T], $G$ - line width $[\mathrm{mm} / \mathrm{s}], A$ - relative intensity [\%]. Compound: $\mathrm{FF}$ - ferrous fumarate, $\mathrm{FH}$ - ferric high spin, $\mathrm{H}$ - hematite.

\begin{tabular}{|c|c|c|c|c|c|c|}
\hline & $I_{s}$ & $Q_{s}$ & $H$ & $G$ & $A$ & comp. \\
\hline \multicolumn{7}{|c|}{ Prenatal $^{\circledR}$ Classic } \\
\hline \multirow{2}{*}{$\mathrm{RT}$} & 1.20 & 2.23 & - & 0.28 & 85 & $\mathrm{FF}$ \\
\hline & 0.18 & 0.41 & - & 0.28 & 15 & FH \\
\hline \multirow{2}{*}{$373 \mathrm{~K}$} & 1.22 & 2.25 & - & 0.30 & 82 & FF \\
\hline & 0.18 & 0.39 & - & 0.25 & 18 & $\mathrm{FH}$ \\
\hline \multirow{2}{*}{$473 \mathrm{~K}$} & 1.21 & 2.24 & - & 0.28 & 79 & $\mathrm{FF}$ \\
\hline & 0.19 & 0.43 & - & 0.30 & 21 & $\mathrm{FH}$ \\
\hline \multirow{3}{*}{$573 \mathrm{~K}$} & 0.39 & 0.80 & - & 0.30 & 68 & $\mathrm{FH}$ \\
\hline & 0.12 & 0.68 & - & 0.25 & 22 & $\mathrm{FH}$ \\
\hline & 0.39 & 0.25 & 50 & 0.35 & 10 & $\mathrm{H}$ \\
\hline \multicolumn{7}{|c|}{ Falvit ${ }^{\circledR}$} \\
\hline \multirow{2}{*}{$\mathrm{RT}$} & 1.23 & 2.23 & - & 0.32 & 65 & FF \\
\hline & 0.19 & 0.42 & - & 0.28 & 35 & $\mathrm{FH}$ \\
\hline \multirow{2}{*}{$373 \mathrm{~K}$} & 1.21 & 2.22 & - & 0.30 & 61 & $\mathrm{FF}$ \\
\hline & 0.19 & 0.40 & - & 0.28 & 39 & $\mathrm{FH}$ \\
\hline \multirow{2}{*}{$473 \mathrm{~K}$} & 1.23 & 2.23 & - & 0.36 & 66 & $\mathrm{FF}$ \\
\hline & 0.18 & 0.39 & - & 0.32 & 34 & FH \\
\hline \multirow{3}{*}{$573 \mathrm{~K}$} & 1.19 & 2.28 & - & 0.20 & 11 & $\mathrm{FF}$ \\
\hline & 0.85 & 0.26 & - & 0.30 & 16 & $\mathrm{FH}$ \\
\hline & 0.13 & 0.49 & - & 0.50 & 73 & $\mathrm{FH}$ \\
\hline \multicolumn{7}{|c|}{ Pregnacare ${ }^{\circledR}$ Original } \\
\hline \multirow{2}{*}{$\mathrm{RT}$} & 1.24 & 2.16 & - & 0.41 & 51 & FF \\
\hline & 0.18 & 0.42 & - & 0.36 & 49 & $\mathrm{FH}$ \\
\hline \multirow{2}{*}{$373 \mathrm{~K}$} & 1.23 & 2.21 & - & 0.28 & 51 & FF \\
\hline & 0.19 & 0.41 & - & 0.28 & 49 & $\mathrm{FH}$ \\
\hline \multirow{3}{*}{$473 \mathrm{~K}$} & 1.21 & 2.80 & - & 0.34 & 14 & FF \\
\hline & 1.22 & 2.05 & - & 0.50 & 39 & $\mathrm{FF}$ \\
\hline & 0.22 & 0.45 & - & 0.54 & 49 & $\mathrm{FH}$ \\
\hline \multirow{3}{*}{$573 \mathrm{~K}$} & 0.20 & 0.53 & - & 0.60 & 68 & $\mathrm{FH}$ \\
\hline & 0.50 & 0.65 & - & 0.50 & 22 & $\mathrm{FH}$ \\
\hline & 0.38 & 0.30 & 51 & 0.70 & 10 & $\mathrm{H}$ \\
\hline
\end{tabular}

prepared in some inclusion complexes. They are increasingly used in the formulations of pharmaceutical products to ensure their safer application and can have the amorphous nature of the structures $[2,9,10]$. After annealing at $473 \mathrm{~K}$, broadening of the absorption line for all the components on the Mössbauer spectra of Falvit ${ }^{\circledR}$ and Prenatal ${ }^{\circledR}$ Classic was observed. In the spectrum of Pregnacare ${ }^{\circledR}$ Original two doublets connected with $\mathrm{FeC}_{4} \mathrm{H}_{2} \mathrm{O}_{4}$ were observed. However, these doublets had different values of quadrupole splitting, which suggests that $\mathrm{Fe}^{2+}$ ions occupy two different iron sites with a slightly different symmetry. This can indicates on some interaction between iron fumarate and inclusion complexes [2]. Above $473 \mathrm{~K}$ temperature significant oxidation of $\mathrm{Fe}^{2+}$ to $\mathrm{Fe}^{3+}$ was observed. In the Mössbauer spectra of Prenatal ${ }^{\circledR}$ Classic and Pregnacare ${ }^{\circledR}$ Original only the doublets connected with ferric ions and small contribution of magnetic component, which was identified as hematite [11], were observed. Small content of ferrous fumarate, about 11\%, in Falvit ${ }^{\circledR}$ was observed after heating in $573 \mathrm{~K}$.

\section{Conclusions}

From the above results we may conclude the following. The XRF method results confirm quantity of iron provided by the manufacturer of the investigated pharmaceutical products.

The results of the applications of the Mössbauer spectroscopy to study various industrial samples of dietary supplements containing iron ions demonstrate wide possibilities of this technique. ${ }^{57} \mathrm{Fe}$ hyperfine parameters of the studied pharmaceuticals indicate the existence of ferrous fumarate. However, the content of this compound in some investigated medicaments and thus $\mathrm{Fe}^{2+}$ ions content cannot be satisfactory for a consumer. Obtained Mössbauer spectra indicated the presence of additional ferric compound with a different relative contribution in each supplement. Hyperfine parameters of ferric doublets are almost the same in each investigated pharmaceutical product. It can suggest that this component is closely connected with ferrous fumarate $\mathrm{FeC}_{4} \mathrm{H}_{2} \mathrm{O}_{4}$ and can be the result of production process effects. Ferrous fumarate contained in dietary supplements is a stable compound up to heating temperature $473 \mathrm{~K}$ which is important news for storage conditions of investigated pharmaceutical products.

\section{References}

[1] N.D. Chasteen, P.M. Harrison, J. Struct. Biol. 126 , 189 (1999).

[2] A.J. Kapor, L.B. Nikolić, V.D. Nikolić, Adv. Technol. 1, 07 (2012).

[3] M.I. Oshtrakh, O.B. Milder, V.A. Semionkin, Hyp. Interact. 156/157, 273 (2004).

[4] B.F. Matzanke, D.J. Ecker, T.S. Yang, B.H. Huynh, G. Muller, K.M. Raymond, J. Bacteriol. 167, 674 (1986).

[5] M.I. Oshtrakh, O.B. Milder, V.A. Semionkin, J. Radioanal. Nucl. Chem. 269, 547 (2006).

[6] M. Kądziołka-Gaweł, M. Michałowska, Acta Phys. Pol. A 127, 653 (2014).

[7] E.M. Coe, L.H. Bowen, R.D. Bereman, J. Inorg. Biochem. 58, 291 (1995).

[8] R. Gozdyra, S.M. Dubiel, J. Cieślak, J. Phys. 217, 012146 (2010).

[9] V. Nikolić, M. Stanković, A. Kapor, Lj. Nikolić, D. Cvetković, J. Stamenković, Pharmazie 59, 845 (2004).

[10] A. Kapor, V. Nikolić, Lj. Nikolić, M. Stanković, M. Cakić, Lj. Stanojević, Cent. Eur. J. Chem. 8, 843 (2010).

[11] G.F. Goya, S.J. Stewart, R.C. Mercader, Solid State Commun. 96, 485 (1995). 